\title{
Female pattern alopecia: current perspectives
}

This article was published in the following Dove Press journal:

International Journal of Women's Health

28 August 2013

Number of times this article has been viewed

\section{Lauren L Levy Jason J Emer}

Department of Dermatology, Mount Sinai School of Medicine, New York, NY, USA
Correspondence: Jason J Emer Mount Sinai School of Medicine, Department of Dermatology, 5 East 98th Street, 5th Floor, New York, NY 10029, USA

Tel + I 2126599530

Fax +I 2123487434
Abstract: Hair loss is a commonly encountered problem in clinical practice, with men presenting with a distinctive pattern involving hairline recession and vertex balding (NorwoodHamilton classification) and women exhibiting diffuse hair thinning over the crown (increased part width) and sparing of the frontal hairline (Ludwig classification). Female pattern hair loss has a strikingly overwhelming psychological effect; thus, successful treatments are necessary. Difficulty lies in successful treatment interventions, as only two medications - minoxidil and finasteride - are approved for the treatment of androgenetic alopecia, and these medications offer mediocre results, lack of a permanent cure, and potential complications. Hair transplantation is the only current successful permanent option, and it requires surgical procedures. Several other medical options, such as antiandrogens (eg, spironolactone, oral contraceptives, cyproterone, flutamide, dutasteride), prostaglandin analogs (eg, bimatoprost, latanoprost), and ketoconazole are reported to be beneficial. Laser and light therapies have also become popular despite the lack of a profound benefit. Management of expectations is crucial, and the aim of therapy, given the current therapeutic options, is to slow or stop disease progression with contentment despite patient expectations of permanent hair regrowth. This article reviews current perspectives on therapeutic options for female pattern hair loss.

Keywords: androgenetic alopecia, female pattern hair loss, minoxidil, finasteride, antiandrogens, spironolactone

\section{Introduction}

Female pattern hair loss (FPHL), or female patterned alopecia, is a form of nonscarring, patterned hair loss occurring commonly in postmenopausal adult women that is characterized by a progressive reduction in hair density on the crown of the scalp with sparing of the frontal hairline (Ludwig scale). The part width progressively increases, most prominently anteriorly, and demonstrates thinning rather than baldness. Temporal recession occurs to a lesser degree in females than in males. A genetically determined shortening of the anagen phase of growth with a constant telogen phase leads to a gradual conversion of terminal (large, thick, and pigmented) hairs into vellus (short, thin, nonpigmented) hairs. Diffuse, rapid onset, nonscarring alopecia is not common in patterned alopecia and should raise suspicion for systemic illness such as iron deficiency, thyroid disease, or syphilis; medication exposure; or an autoimmune etiology. ${ }^{1}$ Perifollicular erythema, pustules, inflammatory papules, scarring, and symptoms such as pain or itching are suggestive of a scarring process.

The prevalence of FPHL increases with age and has a reported incidence of $29 \%$ $38 \%$ in those greater than age 70 , but only $3 \%$ in ages $20-29 .{ }^{2,3}$ Patterned alopecia has 
been reported in a pediatric population chart review, more commonly in females than in males, with an average age of onset at 14.8 years; commonly an underlying endocrine disorder, such as polycystic ovarian syndrome or late-onset adrenal hyperplasia, is suggested. ${ }^{4}$ Despite a significantly large prevalence, many women feel the condition is rare, and are affected socially and psychologically. ${ }^{5}$ Relative to control subjects, women with FPHL completing a standardized questionnaire possessed a more negative body image and a pattern of less adaptive functioning. It was later reported that $55 \%$ of patients who had FPHL displayed symptoms of depression, whereas men were more likely to display anxiety (78\%) or demonstrate aggressiveness or hostility $(22 \%)$. Treatment of hair loss produced an improvement in $89 \%$ of women and $76 \%$ of men. ${ }^{6}$ Further, an increased incidence of coronary artery disease and benign prostatic hypertrophy has been reported in males with pattern hair loss, but not fully confirmed in subsequent studies. ${ }^{7-10}$ Ultimately, patterned alopecia is primarily a cosmetic concern, with some increased risk of increased ultraviolet damage with progressive scalp exposure if sun protection is not utilized consistently.

Currently, topical minoxidil $2 \%$ applied directly to the scalp is the only medication approved by the United States Federal Drug Administration (FDA) for the treatment of FPHL. Other pharmacological agents are used off-label, with variable results. Surgical hair restoration is a final option; however, involvement of the occipital scalp in females often limits its ability and effectiveness. Increased interest in deciphering the molecular mechanisms responsible for this genetically determined condition could potentially open the door for novel treatments that may stimulate new hair growth as well as regenerate older, weakened hairs.

\section{Clinical presentation and diagnosis of female pattern hair loss}

Ludwig first described the three stages of female hair loss in 1977. ${ }^{11}$ Although the exact pattern varies among individuals, the majority demonstrate mid-frontal thinning, while others have temporal and/or vertex involvement (the male type). Some have tried reclassifying FPHL as early onset with or without androgen excess and late onset/postmenopausal with or without androgen excess. ${ }^{12,13}$ However, no major alterations in Ludwig's original classification have been made to date, and treatment modalities assessed in clinical trials still utilize this system, defined by slowly progressive vertex thinning with an increased part width and sparing of the frontal hairline without inflammation or scarring (Table 1 and Figure $1 \mathrm{~A}-\mathrm{C}$ ). Initially, patients may report
Table I Types of alopecia

\begin{tabular}{ll}
\hline Nonscarring & Scarring \\
\hline Female/male pattern hair loss & Chronic cutaneous lupus \\
(androgenetic) & erythematosus (discoid) \\
Alopecia areata & Dermatomyositis \\
Telogen effluvium & Lichen planopilaris \\
Anagen effluvium & Folliculitis decalvans \\
Hypothyroidism & Dissecting cellulitis \\
Syphilis & Central centrifugal cicatricial alopecia \\
Nutritional deficiencies & Tinea capitis \\
Trichotillomania & Tufted folliculitis/pseudopelade \\
Traction alopecia & \\
Monilethrix & \\
\hline
\end{tabular}

increased hair shedding without noticeable change in the overall appearance and thickness of the hair. Not until a significant number of scalp hairs are affected can the physician note the decreased hair density. Generalized, rapid shedding with thinning should prompt a workup for an underlying systemic illness, medication exposure/change, lifestyle modification, or change in hair care practices. Although uncommon in FPHL as compared to male pattern, temporal thinning can be present and may be a first manifestation (Figure 2). In these cases, other causes of temporal thinning, such as traction, telogen effluvium, frontal fibrosing alopecia, and hypothyroidism, should be ruled out. ${ }^{14}$ Patients with FPHL uncommonly report symptoms of itching, burning, or pain of the scalp; however, the presence of inflammation (particularly around hair follicle ostia), scaling, inflammatory papules or pustules, fibrosis with loss of follicular ostia, and/or broken, fragile hairs should prompt a workup to rule out scarring-type alopecia (Figure $3 \mathrm{~A}-\mathrm{C}$ ). It is important to note that violaceous or pink erythema, rather than red, may signify an autoimmune cause such as lupus erythematous, dermatomyositis, or lichen planus (Figure 4A and B). Lymphadenopathy is often a sign of inflammatory tinea capitis and can be easily diagnosed by potassium hydroxide and/or fungal culture of scalp scales and/or hair follicles (Figure 5A and B). Any suggestion of androgen excess such as an abnormal, irregular, or painful menses; increased body hair in uncommon places; obese body habitus; or uncontrolled acne that flares with menstruation should prompt an endocrine workup. ${ }^{15}$ Thus, the diagnosis of FPHL is a combination of a detailed inquiry into the patient's history, including family, social, and medical histories, as well as a comprehensive physical examination with appropriate testing.

Although FPHL has a characteristic pattern indicative of disease, instances where the diagnosis may be in question, given a nonclassic appearance of any of the symptoms or findings described above, should necessitate additional testing 


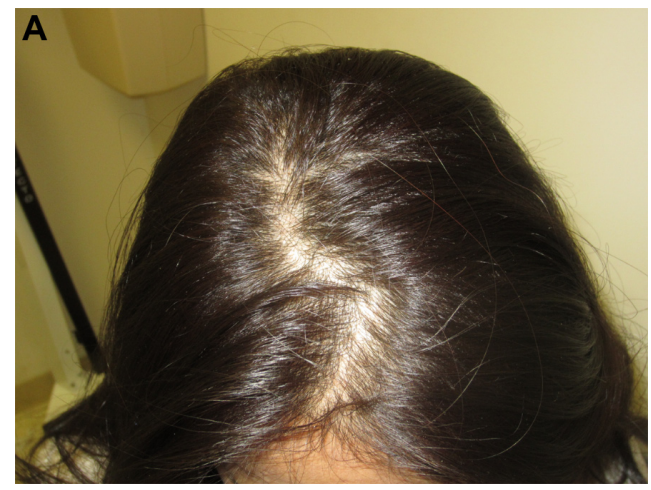

B

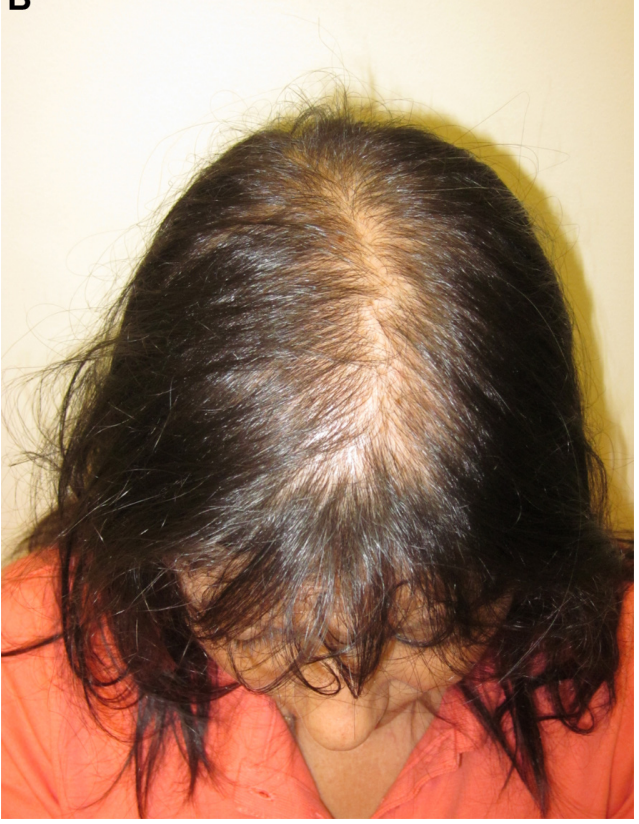

C

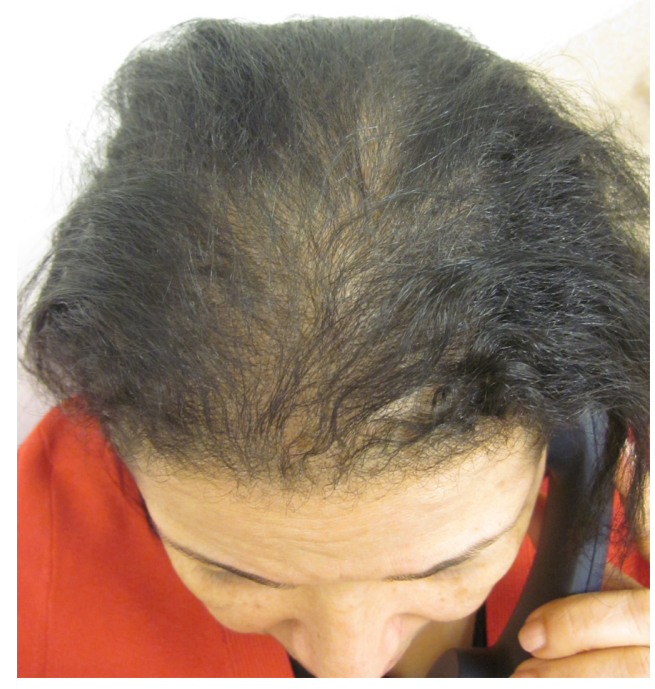

Figure I Ludwig I-III.

Notes: (A) Ludwig I. Mild decrease in hair density on the crown with a barely perceptible increase in the part width. (B) Ludwig II. Moderate decrease in hair density on the crown with noticeable increase in part width. (C) Ludwig III. Severe decrease in hair density on the crown with almost no perceptible part width and thinning of the frontal hairline.

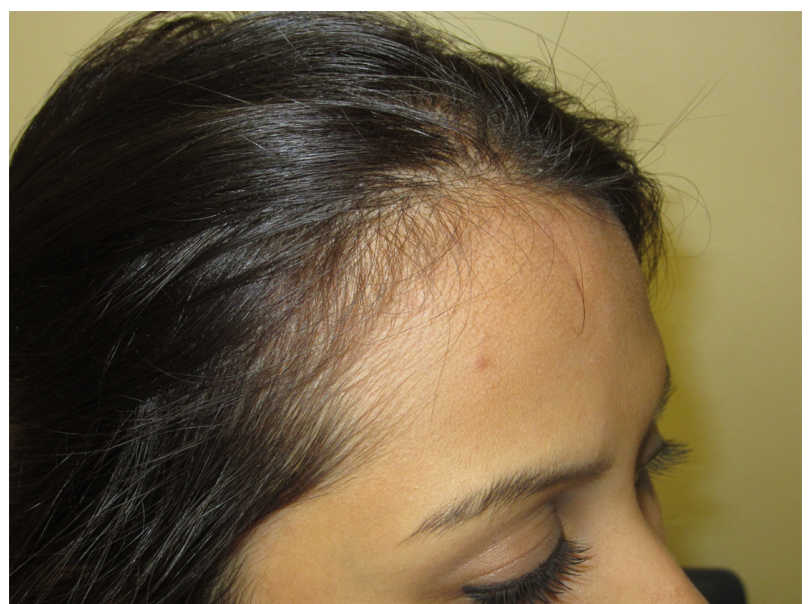

Figure 2 Temporal thinning, early FPHL.

Notes: A patient with family history of androgenetic hair loss, no medical history, and no prominent scalp findings except for a bilateral temporal thinning.

Abbreviation: FPHL, female pattern hair loss

such as hair pull testing, bacterial and/or fungal cultures, laboratory examination, microscopic hair examination, and/ or skin biopsy (Table 2). Scalp biopsy in FPHL will show a decreased terminal-to-vellus hair ratio, indicating miniaturization of the hair follicle as well as an increase in telogen hair follicles. ${ }^{16}$

\section{Pathogenesis}

The hallmark feature of FPHL is the progressive transformation of terminal hair follicles (large, thick, pigmented) to vellus hair follicles (short, thin, nonpigmented), in part due to a genetic predisposition influenced by androgens. ${ }^{17,18}$ Although the process of miniaturization is not fully elucidated, it is known that androgen-responsive hair follicles gradually shorten their anagen (growth phase of the hair follicle) phase, resulting in fewer terminal follicles and more follicles in the shedding phase (telogen). In males, miniaturization is thought to be induced by the conversion of testosterone to dihydrotestosterone (DHT) by the enzyme $5 \alpha$-reductase. A similar conversion is postulated to occur in women; although the role of this conversion and effect on the female hair follicle is less clear. Androgens exert their effect on hair by means of circulating testosterone derived from the adrenal glands, testes, or ovaries. Only free testosterone has the ability to enter cells and undergo conversion to DHT, which then acts on the androgen receptor in susceptible scalp hair follicles to facilitate the unwanted conversion to a miniaturized follicle. ${ }^{19}$ Interestingly, only a minority of females with patterned hair loss have evidence of hyperandrogenism, such as those with polycystic ovarian syndrome, making the role of increased androgen levels in FPHL unclear. ${ }^{20}$ Studies suggest that women may have less 

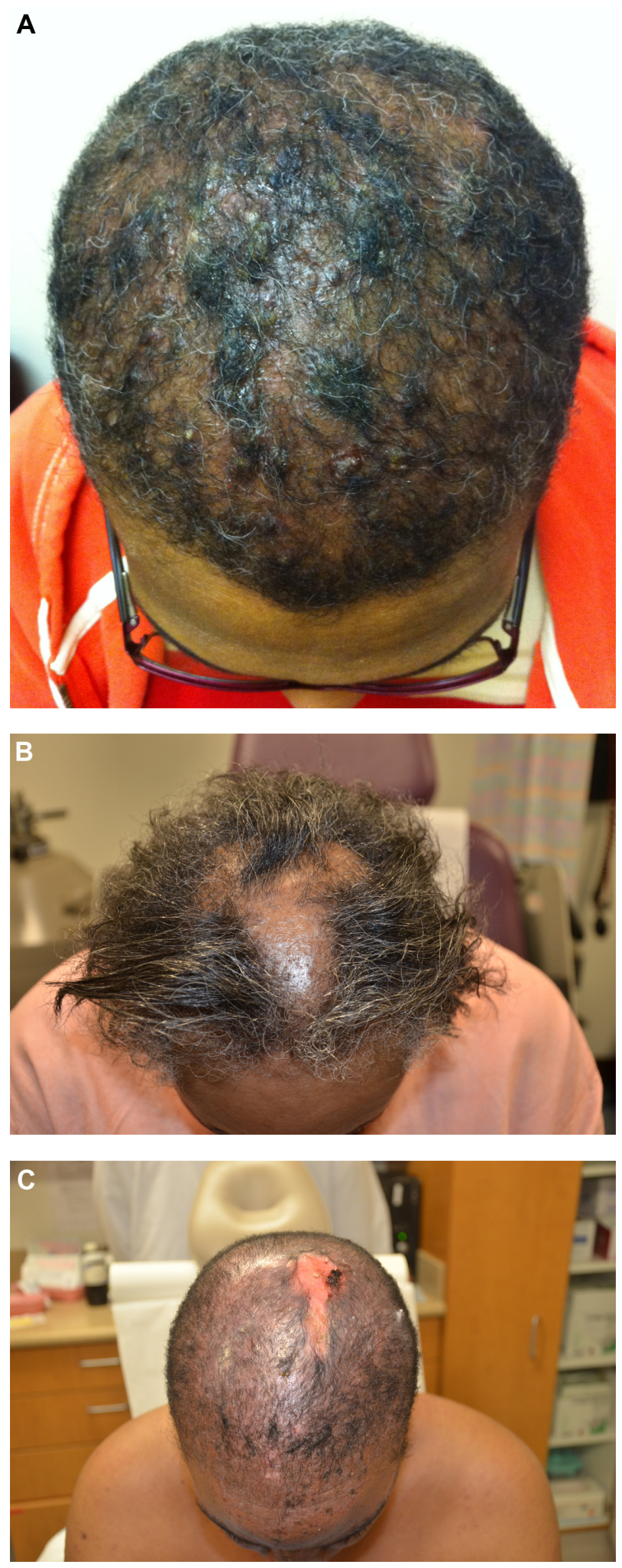

Figure 3 Scarring Alopecias.

Notes: (A) Dissecting cellulitis. Multiple indurated plaques and nodules with serous drainage and crusts and scarring on the scalp. Trapped and broken hairs, loss of follicular ostia, and bogginess are appreciated. (B) Central cicatricial centrifugal alopecia. Patch of alopecia on the central scalp with scarring in a patient with previous history of chemical treatments for many years. (C) Discoid lesions of systemic lupus erythematosus. Scarring alopecia of the scalp with a distinctive background of a faint pink perifollicular erythema.
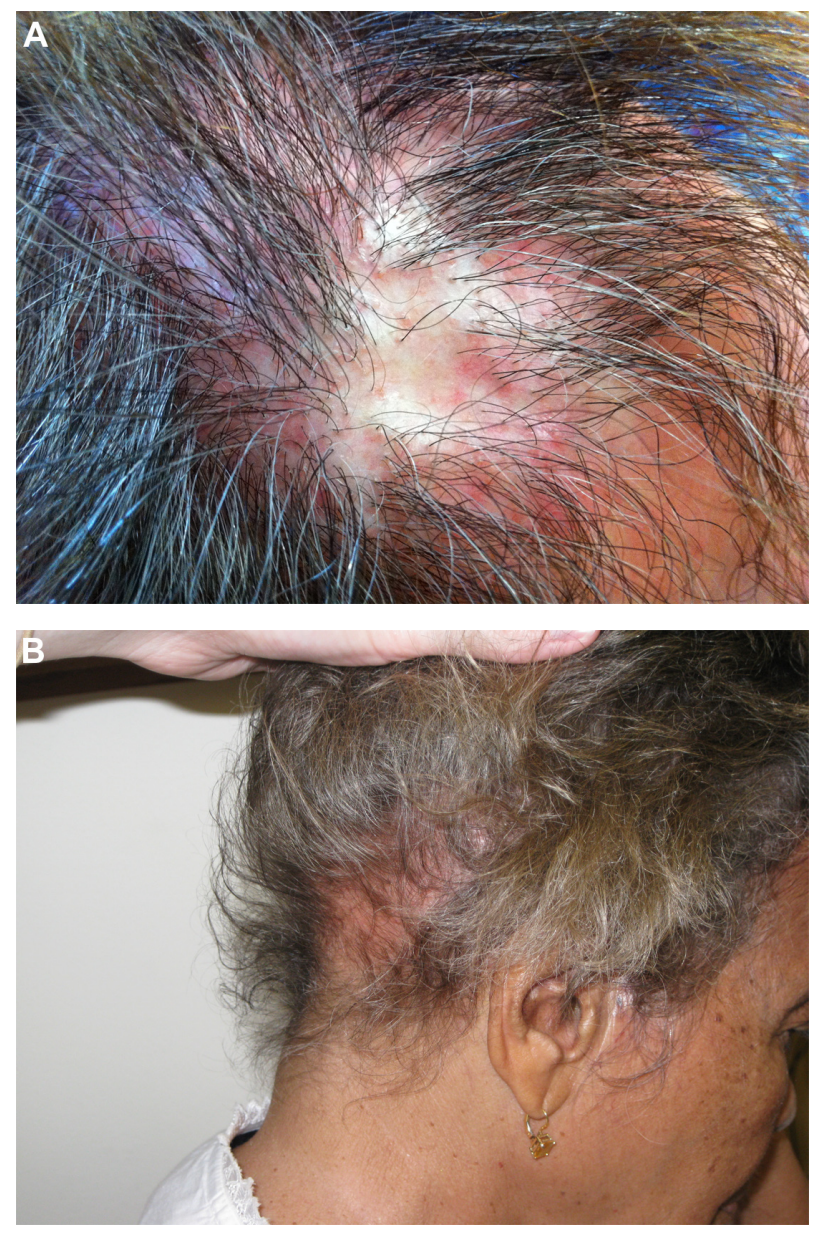

Figure 4 Lichen Planopilaris.

Notes: (A) Lichen planopilaris. Note the striking perifollicular erythema. (B) Telogen effluvium, systemic lupus erythematosus. Decreased hair density in the nuchal area of the scalp with a faint pink erythematous background.

severe hair loss than men due to lower levels of $5 \alpha$-reductase and higher levels of aromatase, an enzyme which converts testosterone to estradiol, in susceptible hair follicles. ${ }^{21}$ A single case report of clinically and histologically proven FPHL with hypopituitarism and undetectable androgens suggests the possibility that this pattern of hair loss also can be induced by events independent of androgens. ${ }^{22}$ The role of estrogen in the pathogenesis is also not definitive, although the increasing prevalence of FPHL in postmenopausal women and the hair loss that occurs following aromatase inhibitor therapy suggest that estrogens may stimulate hair growth. ${ }^{23,24}$ Conversely, genetic studies implicate that an aromatase gene variant resulting in higher levels of estrogen may be associated with the development of FPHL. ${ }^{25}$ Interestingly, the scalps, especially the frontal hair lines, of young women have higher levels of aromatase compared with male scalps, which may explain the decreased severity and relative sparing of the frontal hairline in FPHL. ${ }^{21}$ The aromatase 

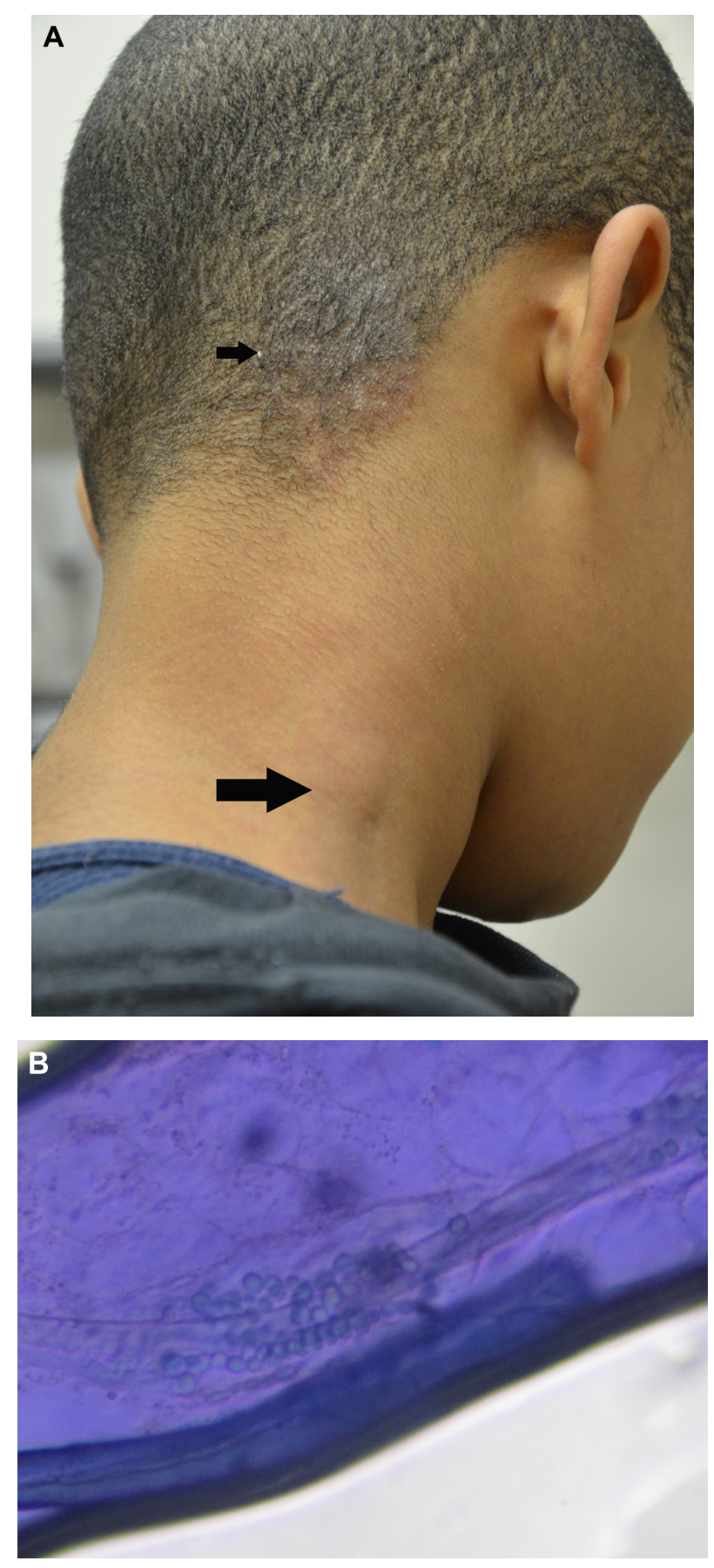

Figure 5 Tinea capitis.

Notes: (A) Scaly plaque with broken hairs and mild bogginess on the posterior right scalp (small arrow). Note the significant regional lymphadenopathy (large arrow). (B) $\mathrm{KOH}$ preparation. Ectothrix involvement of fungal spores is demonstrated on a $\mathrm{KOH}$ preparation of a pulled hair from the scaly plaque of the posterior right scalp. Culture identified Trichophyton tonsurans.

Abbreviation: $\mathrm{KOH}$, potassium hydroxide.

enzyme converts androgens to estrogens, which diminishes the amount of follicular testosterone available for conversion to DHT, and is differentially expressed in the balding and nonbalding scalps of women. Recently, sequence variation in the gene encoding aromatase, CYP19A1 (cytochrome P450, family 19 , subfamily A, polypeptide 1), has been associated with higher circulating levels of estrogens and might influence the risk of developing FPHL. ${ }^{25}$

\section{Treatment}

FPHL is solely a cosmetic concern which fosters psychological distress for patients, as it has a notable impact on quality of life; thus, women seeking evaluation want successful treatments that can minimize further hair loss while also stimulating new hair growth or regrowth of previously lost hairs. Unfortunately, no current therapy is curative, and only one FDA-approved treatment is available at this time. Heightened interest and demand for improved, successful treatments have stimulated an expansion of treatments being implemented. We describe a review and current perspective on the reported treatments to date.

\section{Pharmacologic \\ Minoxidil}

Topical minoxidil 2\% (Rogaine, Johnson and Johnson, New Brunswick, NJ, USA) solution or foam is the only currently approved FDA treatment for FPHL, although a more potent $5 \%$ solution is available and approved for male pattern hair loss (MPHL). Oral minoxidil was introduced prior to the development of the topical form as a treatment for hypertension, given its vasodilatory properties through the stimulation of potassium channels. An observed side effect was hypertrichosis and the reversal of balding in male patients. ${ }^{26}$ Although the subject of over 20 years of research, the stimulatory effects of minoxidil on the hair follicle are not fully known; however, it is known that minoxidil results in an increased growth rate, thicker diameter of the hair follicle, and lengthened anagen phase with a shortened telogen phase of the hair cycle. ${ }^{27}$ Improvement in hair counts may not be due to enhanced blood supply, as survival has been demonstrated in the absence of a blood supply. ${ }^{28}$ Some consider topical minoxidil to be a nonspecific biological response modifier, as it appears to increase conversion of testosterone to less active androgens by increasing activity of 17 $\beta$-hydroxysteroid dehydrogenase, but it also slightly increases $5 \alpha$-reductase activity in cultured balding scalp human dermal papilla cells. ${ }^{29}$

Several randomized controlled trials have proven the effectiveness of topical $2 \%$ minoxidil for FPHL. ${ }^{30,31}$ However, the 5\% concentration has demonstrated much superiority over the $2 \%$ in a double-blind, placebo-controlled, multicenter trial of 381 patients with FPHL who received minoxidil 5\% solution, minoxidil $2 \%$ solution, or placebo 
Table 2 Workup for female pattern hair loss

\begin{tabular}{|c|c|c|}
\hline Test & Findings & Indications \\
\hline \multirow{8}{*}{$\begin{array}{l}\text { Patient } \\
\text { interview/ } \\
\text { history }\end{array}$} & Hair loss from roots & $\begin{array}{l}\text { Alopecia areata, telogen effluvium, } \\
\text { anagen effluvium, androgenetic alopecia }\end{array}$ \\
\hline & Hair breakage & $\begin{array}{l}\text { Tinea capitis, trichotillomania, damage from cosmetics/heat } \\
\text { (trichoschisis, bubble hair), structural abnormalities (Menke's } \\
\text { kinky hair, uncombable hair syndrome, monilethrix) }\end{array}$ \\
\hline & $\begin{array}{l}\text { Medical and psychiatric history, including recent illnesses, } \\
\text { pregnancy, hospitalizations, and symptoms such as weight loss } \\
\text { or fatigue }\end{array}$ & $\begin{array}{l}\text { Telogen effluvium, hypothyroidism, trichotillomania, } \\
\text { medication- induced alopecia }\end{array}$ \\
\hline & Dietary intake & Nutritional deficiency \\
\hline & Family history & Androgenetic alopecia, hypothyroidism, alopecia areata \\
\hline & Medications/chemotherapeutics, illicit substances & Medication-induced hair loss, anagen effluvium \\
\hline & Menstrual/menopause history, use of OCP or hormones & $\begin{array}{l}\text { Endocrinopathy, androgenetic alopecia, medication-induced } \\
\text { hair loss }\end{array}$ \\
\hline & Hair care practices and styling & Traction alopecia, CCCA, pseudopelade \\
\hline Physical & Scarring versus nonscarring & Multiple etiologies (see Table I) \\
\hline \multirow[t]{7}{*}{ exam } & Patchy hair loss & $\begin{array}{l}\text { Syphilis, SLE/DLE, nutritional deficiency, monilethrix, alopecia } \\
\text { areata }\end{array}$ \\
\hline & Thinning on vertex and midline scalp with sparing of frontal hair line & Androgenetic alopecia \\
\hline & Vertex thinning with loss of follicular ostia & CCCA, pseudopelade \\
\hline & Erythema, scale, hair breakage, kerion, occipital lymphadenopathy & Tinea capitis \\
\hline & Signs of virilization, hirsutism, acne & Androgenetic alopecia, endocrinopathy, systemic disease \\
\hline & Perifollicular erythema & LPP, alopecia areata (early) \\
\hline & Pustules & Pustular folliculitis (decalvans, dissecting cellulitis, acne) \\
\hline \multirow[t]{2}{*}{ Pull test } & $0-5$ hairs removed & $\begin{array}{l}\text { Normal, androgenetic alopecia, } \\
\text { trichotillomania }\end{array}$ \\
\hline & $\geq 6$ hairs removed & $\begin{array}{l}\text { Alopecia areata, telogen effluvium, loose anagen syndrome, } \\
\text { medication-induced alopecia }\end{array}$ \\
\hline \multirow[t]{5}{*}{ Hair mount } & Hair with no inner root sheath and bulb with club shape & Telogen hair \\
\hline & Large and pigmented bulb with inner root sheath & Anagen hair \\
\hline & $\begin{array}{l}\text { Nodes along the hair shaft accompanied by breakage (paint brush } \\
\text { fracture) }\end{array}$ & $\begin{array}{l}\text { Trichorrhexis nodosa, (Menke's kinky hair syndrome, } \\
\text { Argininosuccinic aciduria) }\end{array}$ \\
\hline & Intussusception of distal into proximal hair shaft (bamboo hair) & $\begin{array}{l}\text { Trichorrhexis invaginata } \\
\text { (Netherton's syndrome) }\end{array}$ \\
\hline & Tiger-tail banding & Trichothiodystrophy, medication- induced alopecia \\
\hline \multirow[t]{2}{*}{$\mathrm{KOH}$ mount } & Fungal spores present either on or in the hair shaft & Tinea capitis \\
\hline & Nodules or gelatinous sheaths along hair shafts & Piedra, hair casts, pityriasis amiantacea, head lice \\
\hline Laboratory & $\mathrm{CBC}$ and iron panel & Anemia \\
\hline \multirow[t]{5}{*}{ tests } & Thyroid panel & Hypothyroidism \\
\hline & Vitamin D, Vitamin A, Vitamin C, zinc, biotin, folic acid & Nutritional deficiency \\
\hline & ANA screen & SLE/DLE \\
\hline & RPR/VDRL & Syphilis \\
\hline & Prolactin, free and bound testosterone, DHEAS, LH, FSH & Endocrinopathy, systemic disease \\
\hline \multirow[t]{5}{*}{ Scalp biopsy } & $\begin{array}{l}\text { Increased number of vellus hairs, uninvolved area, normal } \\
\text { follicle count }\end{array}$ & Androgenetic alopecia \\
\hline & Absence of inflammation with increased telogen count & Telogen effluvium \\
\hline & Peribulbar lymphocytic infiltrate, increased telogen and catagen hairs & Alopecia areata \\
\hline & $\begin{array}{l}\text { Band-like lymphocytic infiltrate at interface between dermis and } \\
\text { follicular epidermis; perifollicular fibrosis }\end{array}$ & LPP \\
\hline & Vacuolar interface with superficial and deep perivascular and & DLE \\
\hline
\end{tabular}

periadnexal lymphocytic inflammation; follicular plugging Perifollicular mixed inflammatory infiltrate (primarily neutrophilic) with destruction of hair follicles and sebaceous glands, naked hair shafts in dermis; surrounding granulomatous infiltrate (multinucleated giant cells) and fibrosis Decreased number or absent terminal hairs, dermal fibrosis; plasma cells

Pustular folliculitis (acne keloidalis, folliculitis decalvans, dissecting cellulitis)

Scarring alopecia

Abbreviations: ANA, antinuclear antibody; CBC, complete blood count; CCCA, central centrifugal cicatricial alopecia; DHEAS, dehydroepiandrosterone sulfate; DLE, discoid lupus erythematosus; FSH, follicle-stimulating hormone; LH, luteinizing hormone; LPP, lichen planopilaris; OCP, oral contraceptives; RPR, rapid plasma regain; SLE, systemic lupus erythematosus; VDRL, venereal disease research laboratory. 
twice daily. ${ }^{32}$ Both concentrations were without systemic side effects, but patients in the higher concentration group were more likely to experience treatment-related side effects such as scalp pruritus, irritation, and facial hypertrichosis. The application of $5 \%$ minoxidil foam once daily was compared to $2 \%$ minoxidil solution twice daily in a subsequent study, with the goal of finding a solution to the treatment-related side effects observed when administering the $5 \%$ solution twice daily. At 24 weeks, patients in the $5 \%$ once daily group had noninferior hair counts and experienced a nonsignificant improvement in hair counts, hair width, and overall efficacy. Additionally, 5\% foam once daily was more aesthetically pleasing to patients, as there was less facial hypertrichosis and scalp pruritus, and the treatment interfered less with hair styling when compared to the $2 \%$ solution group. This study concluded that $5 \%$ foam once daily was as clinically effective, and offered a significant aesthetic advantage, when compared to the $2 \%$ solution administered twice daily. ${ }^{33}$ Of note, the foam preparation does not contain propylene glycol, which is a frequent cause of irritant dermatitis and may be a reason for the reduced rate of preparation-induced side effects. Further, the solution form has a higher alcohol content, which is also a known irritant.

Most recently, a meta-analysis of randomized controlled trials for treatment interventions in FPHL demonstrated that a greater proportion of patients treated with topical minoxidil reported an increase in hair growth when compared to placebo with a relative risk of 1.86 , indicating that hair growth was more likely to occur in the experimental group. ${ }^{34}$ Of seven included studies, there was an increase of $13.28 / \mathrm{cm}^{2}$ in total hair count when compared to the placebo group. Additionally, adverse events were deemed minimal, but facial hypertrichosis was noted in the $5 \%$ solution used twice daily. Price et al determined that after discontinuation of minoxidil $2 \%$ and $5 \%$ solutions, hair weight and number counts returned to placebo levels in 24 weeks. ${ }^{35}$

Fortunately, minoxidil is inexpensive, generically available, easy to use, and is an effective treatment in restoring the number of nonvellus hairs. Unfortunately, clinical effects are unpredictable, and to some the results may be mild and unappreciated by the patient. Further, if the treatment is not continued continuously and indefinitely, improvements will be lost. It is extremely important to counsel patients that clinical effects may not be noticeable for up to 3-6 months of continued daily use and that hair shedding may occur in the first few months as hairs are transitioned to the anagen phase of growth. If treatment is halted or used inconsistently, there may be lack of appreciable improvement or lost results.
Patients should be informed that the goal of treatment is to prevent further hair loss, but treatment may result in new growth and/or thickening of existing hairs. It is not known if the generic version is any different with regards to efficacy and side effects. No treatment is curative, and many patients may have continued progression despite intervention. Facial hypertrichosis can be reduced by applying the product directly to the scalp in a thin layer so there is no excess (the foam preparation is superior in this regard) well before going to bed, or applying a head covering to limit unwanted spreading of the product. It may be best to recommend the $2 \%$ version to women concerned of this potential unwanted complication, although topical eflornithine (Vaniqa, Skinmedica, Inc, Carlsbad, CA, USA), waxing/plucking, or laser hair removal are options if this complication were to occur. Topical corticosteroids can be used concomitantly to help limit irritant dermatitis and improve seborrhea. Ongoing clinical trials are investigating new formulations, combinations with other medications and/or supplements, and procedures to increase or improve drug delivery. ${ }^{36,37}$

For example, in one study where an investigational combination product called NuH Hair (a novel combination lotion of minoxidil, finasteride, and dutasteride, the overall contents, composition percentages, and formulation methods of which have not been released), applied daily in combination with administration of oral finasteride, topical $5 \%$ minoxidil foam, and/or topical ketoconazole to the scalps of males with patterned hair loss, demonstrated the most significant improvement in hair counts and overall appearance as compared to the investigational product combined with two or fewer other interventions. ${ }^{38}$ In the patients treated with all four interventions, hair growth was noted as early as 14 days. Although this study had very few patients and was not blinded, it demonstrates that combination therapy improves results in the treatment of patterned alopecia and that there is a complex interplay of multiple mechanisms influencing this condition, each requiring specific targeted treatments. Another study using $200 \mathrm{mg}$ of oral spironolactone for 24 weeks in FPHL demonstrated improvements which plateaued but demonstrated further regrowth with the addition of 5\% minoxidil solution twice daily. ${ }^{39}$

A recent in vitro study demonstrated that iontophoresis delivery of minoxidil gel demonstrated greater accumulation of medication into the hair follicle as compared to passive delivery. ${ }^{40}$ Enhanced follicular drug delivery through various mechanisms, here shown with iontophoresis, may be useful to improve the treatment of androgenic alopecia. It has been published that scalp cooling prior to chemotherapy can have 
a preventative impact on the amount of hair loss; although through a different mechanism of hair loss (eg, anagen effluvium), the concept that changing growth parameters such as temperature, $\mathrm{pH}$, blood flow, and nutrient content are important factors in the treatment of patterned alopecia and have the potential to improve treatments in the future. ${ }^{41}$

\section{Reductase Inhibitors}

\section{Finasteride}

Finasteride is a competitive and specific inhibitor of type II $5 \alpha$-reductase - the isotype most common in the hair follicles, prostate, seminal vesicles, epididymis, and liver - which, as described above, blocks the intracellular conversion of testosterone to DHT, a process that appears to play an integral role in the process of hair miniaturization. Type I isotypes are found in sebocytes and hepatocytes. Finasteride has no affinity for the androgen receptor and has no androgenic, antiandrogenic, estrogenic, antiestrogenic, or progestational effects. ${ }^{42}$ It is FDA approved as a $1 \mathrm{mg}$ daily dose (Propecia, Merck and Co, Inc, White House Station, NJ, USA) for the treatment of MPHL and as a $5 \mathrm{mg}$ daily dosage for the treatment of benign prostatic hypertrophy (Proscar, Merck and $\mathrm{Co}$, Inc) ${ }^{43,44}$ It is used off-label in the treatment of postmenopausal FPHL (see below). At the dose of $1 \mathrm{mg}$ daily, an increase in total hair count and anagen hair count as well as reduced progressive hair loss was shown in large clinical trials of males with androgenic alopecia. ${ }^{45,46}$

There are conflicting reports of the effectiveness of finasteride for FPHL. To date, there is only one large-scale, multicenter, randomized placebo-controlled trial, consisting of 137 postmenopausal women with FPHL. ${ }^{47}$ Women were randomized to receive either finasteride $1 \mathrm{mg}$ daily or placebo, with a 1-year follow-up period. No significant change in the hair count between the groups could be identified, and both groups had gradual decreases in hair loss as calculated by the computer-assisted counts. Histological analysis confirmed the clinical findings of lack of increased hair growth or terminal hair differentiation. Thus, the authors concluded that finasteride provided no benefit in increasing hair growth in women with FPHL over a 1-year period.

Contrastingly, there are case reports of higher dosages (up to $5 \mathrm{mg}$ daily) showing benefit with documented improvements in mean hair density and thickness and with few reported side effects (headache, menstrual irregularity, dizziness, and increased body hair growth), even in the absence of signs of hyperandrogenism. ${ }^{4-52}$ Shum reported a series of four women with hyperandrogenism who responded to finasteride, all of whom had hirsutism and elevated testosterone, among other laboratory abnormalities. ${ }^{53}$ Clinical response was seen as early as 6 months and as late as 2.5 years after initiation.

At this point in time, the successful use of finasteride is unpredictable, and may depend on accurately identifying potentially treatment-responsive subsets of patients. In an unblinded open-label trial of 36 women with hyperandrogenic alopecia, patients were randomized to receive finasteride ( $5 \mathrm{mg}$ daily), flutamide ( $250 \mathrm{mg}$ daily) or cyproterone acetate (50 mg daily for 10 days of the month) with ethinyl estradiol for 1 year. ${ }^{54}$ Flutamide induced the most improvement in hair growth; the finasteride group demonstrated no more hair growth than the control group that did not receive any treatment intervention. Greater efforts are needed to classify women accurately into appropriate subsets for which this treatment option may be beneficial. For now, appropriate androgen screening tests should be performed. Fortunately, side effects are minimal in the treatment of FPHL and may include headache, depression, nausea, and/or hot flashes. Medication teratogenicity is a concern, and requires proper patient selection and counseling prior to use. ${ }^{47}$

\section{Dutasteride}

Dutasteride (Avodart, GlaxoSmithKline, Research Triangle Park, NC, USA) is a more potent reductase inhibitor than finasteride, as it inhibits both types I and II $5 \alpha$-reductase. It is currently FDA approved for the treatment of symptomatic benign prostatic hypertrophy $(\mathrm{BPH})$, but not for the treatment of patterned alopecia. ${ }^{55}$ Dutasteride at $0.5 \mathrm{mg}$ daily produces a greater reduction in serum DHT (90\%) as compared to finasteride at $1 \mathrm{mg}$ daily (70\%), as it is more rapid and potent at type II inhibition. In the treatment of MPHL there is clear evidence of its validity, as mean hair counts increased by $12.2 / \mathrm{cm}^{2}$ in the dutasteride group as compared to $4.7 / \mathrm{cm}^{2}$ in the placebo group. ${ }^{56}$ Another study showed similar statistical improvements in pairs of identical twin males with MPHL treated with dutasteride or placebo. ${ }^{57}$ Further, another study documented good outcomes in men with MPHL treated with dutasteride $0.05 \mathrm{mg} /$ day, $0.1 \mathrm{mg} /$ day, $0.5 \mathrm{mg} /$ day, and $2.5 \mathrm{mg} /$ day compared to finasteride $5 \mathrm{mg}$ /day or placebo. ${ }^{58}$ The mean hair count in the $2.5 \mathrm{mg}$ dutasteride group was significantly greater than the finasteride group at both 12 and 24 weeks. At 24 weeks, the percentage of subjects with at least a $10 \%$ increase in hair counts was $0 \%$ for placebo; $17 \%, 38 \%$, $48 \%$, and $56 \%$ for the dutasteride $0.05 \mathrm{mg} /$ day, $0.1 \mathrm{mg} /$ day, $0.5 \mathrm{mg} /$ day, and $2.5 \mathrm{mg} /$ day groups, respectively; and $41 \%$ for finasteride group. One study documented improvement with the addition of dutasteride $0.5 \mathrm{mg}$ daily after finasteride treatment resistance 4 years after daily use. ${ }^{59}$ 
There has been one report of successful treatment with the use of dutasteride for FPHL with no observed side effects in a 46-year-old patient who had failed both minoxidil and finasteride treatment. ${ }^{60}$ Mesotherapy using a dutasteride-containing preparation was found to positively influence hair growth in women with FPHL when compared to saline control after 18 weeks of treatment initiation (total of 12 treatments) ${ }^{6}{ }^{6}$ Topical applications using a liposomal system are being studied for an alternative to oral administration; whether or not this may prove beneficial remains to be seen. ${ }^{62}$

\section{Antiandrogens}

Spironolactone

Over 20 years ago, spironolactone (Aldactone, Pfizer Inc, New York, NY, USA) was prescribed to a woman for treatment of polycystic ovary syndrome and associated hypertension, with the noted benefit of improved hirsutism. Since then it has been used off-label as the primary medical treatment for hirsutism, since it both reduces adrenal androgen production and exerts competitive blockade on androgen receptors in target tissues. ${ }^{63}$ Spironolactone arrests hair loss progression with a favorable long-term safety profile. It is FDA approved for primary hyperaldosteronism; edematous conditions secondary to liver failure, heart failure, or nephrotic syndrome; and hypertension. ${ }^{64}$ Although not currently approved for any dermatologic conditions, it has been accepted as a treatment for acne, hirsutism, and FPHL due to the antiandrogenic properties, as it decreases serum testosterone and lessens its effect in target tissues. ${ }^{63,65,66}$ The ingested drug is absorbed rapidly and metabolized by the liver to canrenone and potassium canrenoate, the active antagonist of aldosterone, and contributes to the potassium-sparing diuretic action. ${ }^{67}$ It also decreases testosterone production in the adrenal gland by depleting microsomal cytochrome $\mathrm{p} 450$ and by affecting the cytochrome p450-dependent enzyme 17a-hydroxylase and desmolase, as well as competitive inhibitor of the androgen receptor blocking the androgen action on the target tissues. $^{63}$

There have been no randomized controlled trials evaluating the efficacy of spironolactone on FPHL, but case reports, series, and an open-label trial support its benefit. ${ }^{68-71}$ In a case study of four patients, spironolactone at the dose of $200 \mathrm{mg}$ daily reduced hair loss by $50 \%-62.9 \%$ and also increased the total number of anagen hairs. ${ }^{69}$ An open-label study of 80 women with biopsy-proven FPHL who either received spironolactone ( $200 \mathrm{mg}$ daily) or cyproterone acetate (either $50 \mathrm{mg}$ daily or $100 \mathrm{mg}$ for 10 days per month if premenopausal) for at least 12 months found no significant differences between the two drugs, but reported that $44 \%(n=35)$ of patients experienced visible hair growth and only $12 \%$ $(\mathrm{n}=10)$ had reduced hair density. ${ }^{71}$ Another published report documented combined benefits with the use of spironolactone $200 \mathrm{mg}$ daily and minoxidil $5 \%$ twice daily, suggesting that the addition of spironolactone to topical minoxidil therapy is a good adjunctive therapy in those patients who have reached a plateau in treatment efficacy with topical therapy alone..$^{38}$ Of note, spironolactone ( $100 \mathrm{mg}$ daily) was equivalent to finasteride (5 $\mathrm{mg}$ daily) or cyproterone acetate $(12.5 \mathrm{mg} /$ day for the first 10 days of the cycle) in the treatment of idiopathic hirsutism but proved to be effective for a longer period of time. ${ }^{72}$

Side effects of spironolactone are dose dependent, primarily result from aldosterone effects on the renal system, and include hypotension, hyperkalemia, fatigue, headache, weight loss, increased urinary frequency, and dry skin. The antiandrogenic effects can predispose patients to menstrual irregularities, gynecomastia, and breast tenderness. Spironolactone is pregnancy category D (considered teratogenic) and should only be used in pregnancy or lactation when maternal benefit outweighs fetal risk. The authors suggest that patients utilize birth control while on this medication; regularly testing urine or serum human chorionic gonadotropin (HCG) along with other laboratory tests, such as potassium and creatinine, is appropriate. Coadministration with an oral contraceptive may be duly beneficial, as the oral contraceptive provides protection against pregnancy and helps limit menstrual irregularities while also improving acne and FPHL. The standard dosage for FPHL is $100-200 \mathrm{mg}$ daily, but should be titrated starting at $50 \mathrm{mg}$ daily (in divided doses of $25 \mathrm{mg}$ twice daily). Lower dosages of 50-75 mg daily may stabilize hair loss, but higher doses are likely to be more beneficial. Blood pressure should be monitored and the dose should be reduced if there are reported symptoms of hypotension such as dizziness or lightheadedness. Rare cases of hepatitis and chloasma have been reported in the literature. ${ }^{73,74}$

\section{Cyproterone acetate}

Cyproterone acetate (Androcur, Schering $\mathrm{GmbH}$ und Co. Produktions KG, Weimar, Germany) is a synthetic steroid with antiandrogen and antigonadotropic properties with weak progesterone activity. It works by competing with DHT for androgen receptor binding. It is used in the treatment of prostate cancer, acne, hirsutism, and is a component of the hormonal cocktail for male-to-female transsexuals. Outside of the US, it is commonly used as a form of birth control when 
combined with estradiol. There is no form of cyproterone acetate currently available in the US.

Studies investigating the efficacy of cyproterone acetate have documented conflicting results, although there are reports of successful treatment of FPHL for those with signs of hyperandrogenism and high ferritin levels. ${ }^{75-77}$ A retrospective review of 228 patients investigated for hyperandrogenism documented that ethinyl estradiol and high-dose cyproterone acetate treatment lowered the hirsutism score by $53.5 \%$ at 1 year and was effective in treating acne and alopecia. ${ }^{78}$ The clinical benefit is ascribed to the peripheral antiandrogenic effect of cyproterone acetate as well as the hormone-suppressive effect of this combination.

Previously mentioned, a study comparing spironolactone and cyproterone acetate showed no difference between the two treatments in patients with FPHL and normal serum androgens. ${ }^{71}$ A 12-month randomized control trial compared topical 2\% minoxidil and cyproterone acetate in 66 women with FPHL. Patients were randomized (33 patients to each group) to receive either topical minoxidil 2\% (2 mL) twice daily combined with an oral contraceptive (30 $\mu \mathrm{g}$ ethinyl estradiol and $75 \mu \mathrm{g}$ gestodene) for 21 of 28 days or cyproterone acetate $50 \mathrm{mg}$ daily for 20 of a 28 day menstrual cycle plus an oral contraceptive (35 $\mu \mathrm{g}$ ethinyl estradiol and $2 \mathrm{mg}$ of cyproterone acetate) for 12 total cycles. ${ }^{79}$ The authors found that minoxidil was more effective in inducing hair growth based on hair count in the absence of hyperandrogenism, hyperseborrhea, and menstrual cycle modifications; when the body mass index (BMI) was low. Cyproterone was more effective when there was evidence of hyperandrogenism. Side effects of cyproterone acetate include weight gain, menstrual irregularities, decreased libido, breast tenderness, and feminization of a male fetus; thus, contraceptive protection is necessary in women of childbearing potential. Larger studies are needed to confirm whether cyproterone acetate with or without ethinyl estradiol and/or spironolactone can ameliorate FPHL independent of hormone levels or not. ${ }^{80}$

\section{Flutamide}

Flutamide is a nonsteroidal selective antiandrogen that inhibits the binding of androgens to their receptors. ${ }^{81}$ A prospective study of 101 patients with FPHL comparing flutamide ( $250 \mathrm{mg} /$ day, $125 \mathrm{mg} /$ day, or $62.5 \mathrm{mg} /$ day) to flutamide combined with an oral contraceptive documented improvement in alopecia scores that lasted up to 2 years; although the results with mildly impressive. ${ }^{82}$ Many patients dropped out of the study due to hepatic dysfunction. Hepatic dysfunction is dose dependent, and liver enzymes should be monitored through treatment, although hepatic failure is rare.

An open-label study suggested that flutamide at a dose of $250 \mathrm{mg}$ daily resulted in the most improvement in hair growth when compared to finasteride $5 \mathrm{mg}$ daily and cyproterone acetate $50 \mathrm{mg}$ daily. ${ }^{54}$ Flutamide produced a reduction in Ludwig scores of $21 \%$, whereas finasteride and cyproterone acetate did not produce statistically significant changes. Flutamide may be a treatment option in patients with normal androgen levels, as evidenced by an increased hair density seen in a 35-year-old female treated with flutamide $(250 \mathrm{mg}$ daily) in combination with topical minoxidil 5\% after failing spironolactone treatment. ${ }^{83}$

\section{Prostaglandin analogs}

The prostaglandin analogs (PGAs), such as latanoprost (Xalatan, Pfizer Inc), travoprost (Travatan, Alcon Laboratories Inc, Fort Worth, TX, USA), and bimatoprost (Lumigan, Allergan Inc, Irvine, CA, USA), are used topically in the treatment of glaucoma and ocular hypertension. ${ }^{84-86}$ Serendipitously, this class of medications, when used for the treatment of glaucoma, was found to stimulate eyelash growth and pigmentation. Bimatoprost (Latisse, Allergan Inc) is the only FDA-approved topical for hypotrichosis of the eyelashes. ${ }^{87,88}$ When applied nightly, there is an increase in anagen follicles, resulting in thicker, darker, and longer eyelashes. ${ }^{89}$ Hair growth is achieved through induction of the anagen phase in telogen hair follicles through targeting the dermal papilla. ${ }^{90}$

The use of these agents in patterned alopecia is suggested by the literature but not yet supported by trials. Latanoprost stimulated hair growth in the macaque model of androgenetic hair loss with topical daily application for 5 months, with $5 \%-10 \%$ conversion of vellus hairs to intermediate or terminal hairs with a high dose $(500 \mu \mathrm{g} / \mathrm{mL}) .{ }^{91}$ Subsequently, a randomized comparison study evaluated the use of topical latanoprost $0.1 \%$ versus placebo in 16 men with mild (Hamilton II-III) patterned alopecia who applied the solutions daily to two minizones of the scalp. At 24 weeks, there was a significant increase in hair density of both terminal and vellus hairs on the latanoprost-treated site when compared to baseline and to the placebo-treated site. ${ }^{92}$ Fifty percent were defined as having a "good clinical response" (treatment better than placebo in at least two of the study criteria), 44\% had "no clinical response" (no difference between placebo and treatment), and 6\% had a "bad clinical response" (placebo better than treatment). Adverse events in this study were folliculitis, erythema, and sensation of burning. This is a similar 
side effect profile when latanoprost is used in the treatment of glaucoma, and includes iridial and periocular pigmentation, erythema, telangiectasia, extra eyelash rows, pigmentation, and eyelash curvature.

Scalp injections of bimatoprost $0.03 \%$ weekly for 12 weeks and then biweekly for 4 weeks was attempted as a novel treatment of FPHL in a 59-year-old female, without success. ${ }^{93}$ This novel treatment reinforces that further pilot studies with PGAs are necessary in order to determine efficacy. A clinical trial to establish the efficacy of three formulations of bimatoprost solution compared with minoxidil in women with FPHL has been completed without published results. ${ }^{94}$ The use of PGAs in the treatment of other hair loss conditions such as alopecia areata show conflicting results. ${ }^{95,96}$

\section{Other treatments}

\section{Ketoconazole}

Ketoconazole is an imidazole antifungal agent with antiinflammatory effects proving successful in the treatment of seborrhoeic dermatitis. Studies using ketoconazole shampoo $2 \%$ on MPHL showed increased hair density in addition to increased size and proportion of anagen follicles when compared to those using a nonmedicated shampoo. ${ }^{97}$ The addition of finasteride ( $1 \mathrm{mg}$ daily) documented an additive effect to the use of topical ketoconazole in the treatment of MPHL. ${ }^{98}$ Further, murine experiments have shown increased hair growth following the use of topical ketoconazole in a $95 \%$ ethanol solution, suggesting its potential benefit in the treatment of patterned hair loss. ${ }^{99}$ Oral administration of ketoconazole is known to have antiandrogen effects, as it can inhibit steroid biosynthesis of testicular and adrenal androgens. ${ }^{100}$ Therefore, it is believed that topical application may have efficacy in suppressing androgen receptor activity and be important in hormonally stimulated hair loss. There are currently no published studies on the use of ketoconazole in FPHL, and it is unknown if it is or will be a useful modality for this disorder.

\section{Estrogens}

As described above, there is a paucity of data suggesting nonandrogenic signals may have influence over the follicular unit with regards to FPHL. Despite this, estrogens have been shown to decrease the duration of the telogen phase and increase the duration of the anagen phase in the human scalp. ${ }^{101}$ Additionally, the discovery of the estrogen receptor beta and the polymorphism in the gene encoding aromatase (CYP19A1) in hair suggests estrogen's influence on the hair follicle growth cycles. ${ }^{24,102}$ This seems to correlate with the perceived view of hair thinning and decreased growth rate in many peri- and postmenopausal women. ${ }^{103}$ In vitro studies have shown that human scalp hair follicles exposed to estradiol results in decreased growth, where cells of the dermal papilla responded with proliferation. ${ }^{104,105}$ Nevertheless, the biological activity of estrogen in the hair follicle is likely a result of a complex interplay between genetic factors and hormonal influence on a multitude of signaling pathways. ${ }^{106}$

When used systemically, estrogens act to decrease circulating testosterone through upregulation of sex hormonebinding globulin. Interestingly, the use of oral contraceptives, their cessation, and hormone replacement therapy have all been reported to cause temporary hair shedding or telogen effluvium. Whether the progestin component plays a role is debated. As described earlier, women with breast cancer who take medications aimed at decreasing the effect of estrogens (selective estrogen receptor modulators) or medications that block the peripheral production of estrogen (aromatase inhibitors) commonly report hair loss. Further, in pregnancy, scalp hair diameter has been shown to increase; likely not a result of estrogen alone, but a complex interaction with other hormones including progesterone and prolactin. ${ }^{107}$ One report documented complete hair regrowth in a transsexual individual with MPHL on estrogen. ${ }^{108}$

In Europe, topical estrogens are available and used for various hair disorders. A recent study of topical estrogen (fulvestrant) documented increased hair growth in a murine model, but failed to show improvement in men and women with pattern baldness. ${ }^{109}$ Contrastingly, topical $17 \alpha$-estradiol demonstrated increased hair counts and diameter after 8 months of use in a Phase IV open-label trial in Korean women. ${ }^{25}$ A comparison between topical minoxidil 2\% solution and topical alfatradiol in the treatment of FPHL demonstrated positive results only in the group treated with minoxidil after 6 months of daily use. ${ }^{110}$ Patients crossed over from topical alfatradiol to minoxidil noticed increase in cumulative hair thickness and absolute hair density. Of note, the alfatradiol group remained unchanged, which may suggest that topical estrogen can stabilize or decelerate progressive hair loss. At this point in time, there is insufficient evidence to support the use of estrogens in FPHL, and additional studies are needed to validate their use. ${ }^{111}$

\section{Nutritional supplementation}

It has been suggested that nutritional supplements with vitamins, minerals, and/or antioxidants may help in hair 
Table 3 Nutritional supplements with anecdotal evidence of hair growth

Biotin (Vitamin B7)

$B$ complex vitamins

Zinc

Copper

Iron

Vitamin C

Vitamin E

Vitamin A

Coenzyme Q10

Saw palmetto

Green tea extract

Methylsulfonylmethane (MSM)

Beta-sitosterol

Rosemary

Lavender

Thyme

growth and health ${ }^{112-116}$ (Table 3). Since there is a lack of randomized controlled trials supporting any of these claims, we will not discuss this topic further in this paper. However, a list is provided, and practitioners should be familiar with those available so as to avoid potential side effects or drug interactions if employed. Supplementation may be beneficial in combination with evidence-based treatments.

\section{Low-level light therapy}

Low-level light therapy (LLLT) utilizes devices with light-emitting diodes (650-900 nm) which alter cellular function, such as levels of prostaglandins, cytokines, and tumor necrosis factor, and influence reversal of oxidative stress, such as those induced by mitochondrial redox reactions. ${ }^{117,118}$ The mechanisms by which LLLT can induce hair growth are not clear, but it is suggested that light may activate dormant hair follicles, increase blood flow to the hair follicles, or upregulate the production of adenosine triphosphate (ATP) by mitochondria to stimulate hair into the anagen phase. ${ }^{119}$

Clinical evidence for the induction of hair growth following diode laser treatment stems from reports of paradoxical hypertrichosis in adjacent areas following laser hair removal treatments as well as alopecia areata improving from ultraviolet light therapy. ${ }^{120,121}$ In 2007, the HairMax laser comb (Lexington International LLC, Boca Raton, FL, USA) was approved by the FDA as the first and only medical laser device marketed for the treatment of MPHL, with subsequent approval for FPHL in 2011. ${ }^{122}$ This device has nine beams with a wavelength of $655 \mathrm{~nm}$ and utilizes hair combs that align with the laser beam, so that energy is targeted toward the scalp when the hair is parted with the comb.
A double-blind, sham device-controlled, multicenter, randomized 26-week trial of the HairMax device for MPHL demonstrated significantly greater increases in mean terminal hair density than in subjects in the sham device group at 26 weeks. ${ }^{123}$ Subjects used the device three times a week for 15 minutes. A smaller prospective study of 35 male and female patients with patterned alopecia reported increased hair counts and tensile strength of the hair in both the temporal and vertex areas for men and women. ${ }^{124}$

Most recently, The Oaze (Won Technology, Daejoen, Korea), a helmet-shaped LLLT device emitting wavelengths of $630 \mathrm{~nm}, 650 \mathrm{~nm}$, and $660 \mathrm{~nm}$, was evaluated in a randomized, double-blind, sham device-controlled trial including both men and women with patterned hair loss. ${ }^{125}$ After 18-minute daily treatments for 24 weeks, mean hair diameter improved significantly in the treatment group when compared to the sham device group. Investigator global assessments showed improvements in the treatment group over the sham group through the course of the study; however, patient perception was that of no improvement for both groups.

At-home laser treatment is appealing, as these treatments are convenient, easy to use, have minimal side effects, and are less costly than continued medical therapies. Reported adverse events include scalp irritation or erythema. Such treatments may offer a viable option for those who are medication adverse, or as a useful adjunct to other medical or surgical therapies.

\section{Hair transplant surgery}

Females who have failed other therapies but desire a permanent solution to hair loss have the option of hair transplantation. Unlike men, however, donor site availability in females may be limited given the diffuse nature of the hair loss pattern; this should be discussed with those considering therapy. Transplantation procedures are often time consuming, uncomfortable, and expensive, and may not give an ultimate cure even after multiple treatments. A realistic goal should be an improvement in hair density rather than complete reversal. ${ }^{126}$ Complications include temporary loss of hair adjacent to the donor and recipient area due to decreased blood supply at the incision site, infection, pain, and failure of the transplanted hair to grow. The use of topical minoxidil may increase hair density and speed the regrowth of transplanted follicles following the surgical procedure. ${ }^{127}$ Referral to a dedicated and reputable hair transplantation specialist should be offered to those patients who desire this therapy. Wigs and/or hair camouflage 
can be offered as a last option in those unwilling to have surgery and/or those for whom medical therapy has not proven beneficial.

\section{Conclusion}

Patterned hair loss is distressing to both the patient and the practitioner. No treatments are curative, and most therapies for FPHL are only partially effective. As hair loss can be cosmetically and psychologically distressing, it is important for practitioners to address diagnosis and treatment early to catch the opportunity for therapeutic success. Although only one therapy is currently FDA approved for the medical treatment of FPHL, there are many other options discussed here that can be utilized with relatively minimal side effects if used properly. The goal of therapy should be to stop further progression and improve the density of the hair that remains. Lack of disease progression while undergoing medical therapy should be considered a treatment success, and that concept should be discussed with patients at the first visit. Given the number of patients with this condition, it is necessary to further investigate the pathophysiology of this condition so as to better propose future treatment options. Novel techniques, such as autologous stem cell or platelet rich plasma treatments, may offer improved results over the long term, but this remains to be seen.

\section{Disclosure}

The authors report no conflicts of interest in this work.

\section{References}

1. Olsen EA, Reed KB, Cacchio PB, Caudill L. Iron deficiency in female pattern hair loss, chronic telogen effluvium, and control groups. $J \mathrm{Am}$ Acad Dermatol. 2010;63(6):991-999.

2. Norwood OT. Incidence of female androgenetic alopecia (female pattern alopecia). Dermatol Surg. 2001;27(1):53-54.

3. Birch MP, Messenger JF, Messenger AG. Hair density, hair diameter and the prevalence of female pattern hair loss. Br J Dermatol. 2001;144(2):297-304.

4. Gonzalez ME, Cantatore-Francis J, Orlow SJ. Androgenetic alopecia in the paediatric population: a retrospective review of 57 patients. Br J Dermatol. 2010;163(2):378-385.

5. Cash TF, Price VH, Savin RC. Psychological effects of androgenetic alopecia on women: comparisons with balding men and with female control subjects. J Am Acad Dermatol. 1993;29(4):568-575.

6. Camacho FM, García-Hernández M. Psychological features of androgenetic alopecia. J Eur Acad Dermatol Venereol. 2002;16(5): 476-480.

7. Lesko SM, Rosenberg L, Shapiro S. A case-control study of baldness in relation to myocardial infarction in men. JAMA. 1993;269(8): 998-1003.

8. Shahar E, Heiss G, Rosamond WD, Szklo M. Baldness and myocardial infarction in men: the atherosclerosis risk in communities study. Am J Epidemiol. 2008;167(6):676-683.

9. Oh BR, Kim SJ, Moon JD, et al. Association of benign prostatic hyperplasia with male pattern baldness. Urology. 1998;51(5): 744-748.
10. Faydaci G, Bilal E, Necmettin P, Fatih T, Asuman O, Uğur K. Baldness, benign prostate hyperplasia, prostate cancer and androgen levels. Aging Male. 2008;11(4):189-192.

11. Ludwig E. Classification of the types of androgenetic alopecia (common baldness) occurring in the female sex. Br J Dermatol. 1977;97(3): 247-254.

12. Olsen EA, Hordinsky M, Roberts JL, Whiting DA; Dermatologic Consortium for Women's Health. Female pattern hair loss. J Am Acad Dermatol. 2002;47(5):795.

13. Olsen EA. Current and novel methods for assessing efficacy of hair growth promoters in pattern hair loss. JAm Acad Dermatol. 2003;48(2): $253-262$.

14. Birch MP, Lalla SC, Messenger AG. Female pattern hair loss. Clin Exp Dermatol. 2002;27(5):383-388.

15. Sinclair RD, Dawber RP. Androgenetic alopecia in men and women. Clin Dermatol. 2001;19(2):167-178.

16. Whiting DA, Waldstreicher J, Sanchez M, Kaufman KD. Measuring reversal of hair miniaturization in androgenetic alopecia by follicular counts in horizontal sections of serial scalp biopsies: results of finasteride $1 \mathrm{mg}$ treatment of men and postmenopausal women. J Investig Dermatol Symp Proc. 1999;4(3):282-284.

17. Messenger AG, Sinclair R. Follicular miniaturization in female pattern hair loss: clinicopathological correlations. Br J Dermatol. 2006;155(5): 926-930.

18. Randall VA. Androgens and hair growth. Dermatol Ther. 2008;21(5): 314-328.

19. Price VH. Androgenetic alopecia in women. J Investig Dermatol Symp Proc. 2003;8(1):24-27.

20. Futterweit W, Dunaif A, Yeh HC, Kingsley P. The prevalence of hyperandrogenism in 109 consecutive female patients with diffuse alopecia. J Am Acad Dermatol. 1988;19(5 Pt 1):831-836.

21. Sawaya ME, Price VH. Different levels of 5alpha-reductase type I and II, aromatase, and androgen receptor in hair follicles of women and men with androgenetic alopecia. J Invest Dermatol. 1997;109(3): 296-300.

22. Orme S, Cullen DR, Messenger AG. Diffuse female hair loss: are androgens necessary? Br J Dermatol. 1999;141(3):521-523.

23. Yip L, Rufaut N, Sinclair R. Role of genetics and sex steroid hormones in male androgenetic alopecia and female pattern hair loss: an update of what we now know. Australas J Dermatol. 2011;52(2):81-88.

24. Conrad F, Paus R. Estrogens and the hair follicle. $J$ Dtsch Dermatol Ges. 2004;2(6):412-423.

25. Yip L, Zaloumis S, Irwin D, et al. Gene-wide association study between the aromatase gene (CYP19A1) and female pattern hair loss. $\mathrm{Br} J$ Dermatol. 2009;161(2):289-294.

26. Zappacosta AR. Reversal of baldness in patient receiving minoxidil for hypertension. N Engl J Med. 1980;303(25):1480-1481.

27. Messenger AG, Rundegren J. Minoxidil: mechanisms of action on hair growth. Br J Dermatol. 2004;150(2):186-194.

28. Price VH. Treatment of hair loss. N Engl J Med. 1999;341(13): 964-973.

29. Haber RS. Pharmacologic management of pattern hair loss. Facial Plast Surg Clin North Am. 2004;12(2):181-189.

30. Whiting DA, Jacobson C. Treatment of female androgenetic alopecia with minoxidil 2\%. Int J Dermatol. 1992;31(11):800-804.

31. Jacobs JP, Szpunar CA, Warner ML. Use of topical minoxidil therapy for androgenetic alopecia in women. Int J Dermatol. 1993;32(10): $758-762$.

32. Lucky AW, Piacquadio DJ, Ditre CM, et al. A randomized, placebo-controlled trial of $5 \%$ and $2 \%$ topical minoxidil solutions in the treatment of female pattern hair loss. JAm Acad Dermatol. 2004;50(4): $541-553$.

33. Blume-Peytavi U, Hillmann K, Dietz E, Canfield D, Garcia Bartels N. A randomized, single-blind trial of $5 \%$ minoxidil foam once daily versus $2 \%$ minoxidil solution twice daily in the treatment of androgenetic alopecia in women. J Am Acad Dermatol. 2011;65(6): 1126-1134. e2.

34. van Zuuren EJ, Fedorowicz Z, Carter B, Andriolo RB, Schoones J. Interventions for female pattern hair loss. Cochrane Database Syst Rev. 2012;5:CD007628. 
35. Price VH, Menefee E, Strauss PC. Changes in hair weight and hair count in men with androgenetic alopecia, after application of $5 \%$ and $2 \%$ topical minoxidil, placebo, or no treatment. J Am Acad Dermatol. 1999;41(5 Pt 1):717-721.

36. Johnson and Johnson Consumer and Personal Products Worldwide. A phase 3 multi-center parallel design clinical trial to compare the efficacy and safety of $5 \%$ minoxidil foam vs $2 \%$ minoxidil solution in females for the treatment of female pattern hair loss androgenetic alopecia. Available from http://clinicaltrials.gov/ show/NCT01145625. NLM identifier: NCT01145625. Accessed April 10, 2013.

37. Thuangtong R. Pilot study of the efficacy in treatment of female pattern hair loss using 5\% minoxidil solution combined with oral chelated zinc supplement. Available from: http://clinicaltrials.gov/ ct2/show/NCT01662089. NLM identifier: NCT01662089. Accessed April 10, 2013.

38. Rafi AW, Katz RM. Pilot study of 15 patients receiving a new treatment regimen for androgenic alopecia: the effects of atopy on AGA. ISRN Dermatol. 2011;2011:241953.

39. Hoedemaker C, van Egmond S, Sinclair R. Treatment of female pattern hair loss with a combination of spironolactone and minoxidil. Australas J Dermatol. 2007;48(1):43-45.

40. Gelfuso GM, Gratieri T, Delgado-Charro MB, Guy RH, Vianna Lopez RF. Iontophoresis-targeted, follicular delivery of minoxidil sulfate for the treatment of alopecia. J Pharm Sci. 2013;102(5):1488-1494.

41. van den Hurk CJ, van den Akker-van Marle ME, Breed WP, van de Poll-Franse LV, Nortier JW, Coebergh JW. Impact of scalp cooling on chemotherapy-induced alopecia, wig use and hair growth of patients with cancer. Eur J Oncol Nurs. Epub April 6, 2013.

42. Gormley GJ. Finasteride: a clinical review. Biomed Pharmacother. 1995;49(7-8):319-324.

43. Propecia [package insert]. White House Station, NJ: Merck and Co, Inc; Oct 2004.

44. Proscar [package insert]. White House Station, NJ: Merck and Co, Inc; Jan 2013.

45. Kaufman KD, Olsen EA, Whiting D, et al. Finasteride in the treatment of men with androgenetic alopecia. Finasteride Male Pattern Hair Loss Study Group. J Am Acad Dermatol. 1998;39(4 Pt 1): 578-589.

46. Leyden J, Dunlap F, Miller B, et al. Finasteride in the treatment of men with frontal male pattern hair loss. JAm Acad Dermatol. 1999;40(6 Pt 1): 930-937.

47. Price VH, Roberts JL, Hordinsky M, et al. Lack of efficacy of finasteride in postmenopausal women with androgenetic alopecia. J Am Acad Dermatol. 2000;43(5 Pt 1):768-776.

48. Yeon JH, Jung JY, Choi JW, et al. $5 \mathrm{mg}$ /day finasteride treatment for normoandrogenic Asian women with female pattern hair loss. J Eur Acad Dermatol Venereol. 2011;25(2):211-214.

49. Trüeb RM; Swiss Trichology Study Group. Finasteride treatment of patterned hair loss in normoandrogenic postmenopausal women. Dermatology. 2004;209(3):202-207.

50. Boychenko O, Bernstein RM, Schweiger ES. Finasteride in the treatment of female pattern (androgenic) alopecia: a case report and review of the literature. Cutis. 2012;90(2):73-76.

51. Thai KE, Sinclair RD. Finasteride for female androgenetic alopecia. Br J Dermatol. 2002;147(4):812-813.

52. Valsecchi R, Leghissa P, Riva M. Female androgenetic alopecia treated by finasteride: a case forward. Acta Derm Venereol. 2004;84(6): $488-489$.

53. Shum KW, Cullen DR, Messenger AG. Hair loss in women with hyperandrogenism: four cases responding to finasteride. J Am Acad Dermatol. 2002;47(5):733-739.

54. Carmina E, Lobo RA. Treatment of hyperandrogenic alopecia in women. Fertil Steril. 2003;79(1):91-95.

55. Avodart [package insert]. Research Triangle Park, NC: GlaxoSmithKline; Oct 2012 .
56. Eun HC, Kwon OS, Yeon JH, et al. Efficacy, safety, and tolerability of dutasteride $0.5 \mathrm{mg}$ once daily in male patients with male pattern hair loss: a randomized, double-blind, placebo-controlled, phase III study. J Am Acad Dermatol. 2010;63(2):252-258.

57. Stough D. Dutasteride improves male pattern hair loss in a randomized study in identical twins. J Cosmet Dermatol. 2007;6(1):9-13.

58. Olsen EA, Hordinsky M, Whiting D, et al; Dutasteride Alopecia Research Team. The importance of dual 5alpha-reductase inhibition in the treatment of male pattern hair loss: results of a randomized placebo-controlled study of dutasteride versus finasteride. J Am Acad Dermatol. 2006;55(6):1014-1023.

59. Boyapati A, Sinclair R. Combination therapy with finasteride and lowdose dutasteride in the treatment of androgenetic alopecia. Australas $J$ Dermatol. 2013;54(1):49-51.

60. Olszewska M, Rudnicka L. Effective treatment of female androgenic alopecia with dutasteride. J Drug Dermatol. 2005;4(5):637-640.

61. Moftah N, Moftah N, Abd-Elaziz G, et al. Mesotherapy using dutasteride-containing preparation in treatment of female pattern hair loss: photographic, morphometric and ultrustructural evaluation. J Eur Acad Dermatol Venereol. 2013;27(6):686-693.

62. Sharma P, Jain D, Maithani M, et al. Development and characterization of dutasteride bearing liposomal systems for topical use. Curr Drug Discov Technol. 2011;8(2):136-145.

63. Rathnayake D, Sinclair R. Innovative use of spironolactone as an antiandrogen in the treatment of female pattern hair loss. Dermatol Clin. 2010;28(3):611-618.

64. Aldactone [package insert]. New York, NY: Pfizer Inc; Oct 2012.

65. Rathnayake D, Sinclair R. Use of spironolactone in dermatology. Skinmed. 2010;8(6):328-332.

66. Katsambas AD, Dessinioti C. Hormonal therapy for acne: why not as first line therapy? Facts and controversies. Clin Dermatol. 2010;28(1):17-23.

67. Gómez R, Núñez L, Caballero R, Vaquero M, Tamargo J, Delpón E. Spironolactone and its main metabolite canrenoic acid block hKv1.5, Kv4.3 and Kv7.1 + mink channels. Br J Pharmacol. 2005;146(1): 146-161.

68. Yazdabadi A, Green J, Sinclair R. Successful treatment of female-pattern hair loss with spironolactone in a 9-year-old girl. Australas J Dermatol. 2009;50(2):113-114.

69. Adamopoulos DA, Karamertzanis M, Nicopoulou S, Gregoriou A. Beneficial effect of spironolactone on androgenic alopecia. Clin Endocrinol (Oxf). 1997;47(6):759-760.

70. Burke BM, Cunliffe WJ. Oral spironolactone therapy for female patients with acne, hirsutism or androgenic alopecia. Br J Dermatol. 1985;112(1):124-125.

71. Sinclair R, Wewerinke M, Jolley D. Treatment of female pattern hair loss with oral antiandrogens. Br J Dermatol. 2005;152(3):466-473.

72. Lumachi F, Rondinone R. Use of cyproterone acetate, finasteride, and spironolactone to treat idiopathic hirsutism. Fertil Steril. 2003;79(4): 942-946.

73. Thai KE, Sinclair RD. Spironolactone-induced hepatitis. Australas $J$ Dermatol. 2001;42(3):180-182.

74. Hughes BR, Cunliffe WJ. Tolerance of spironolactone. Br J Dermatol. 1988;118(5):687-691.

75. Brzezińska-Wcisło L. [Assessment of efficacy of Diane-35 in androgenetic feminine alopecia.] Wiad Lek. 2003;56(3-4):202-205. Polish.

76. Dinh QQ, Sinclair R. Female pattern hair loss: current treatment concepts. Clin Interv Aging. 2007;2(2):189-199.

77. Rushton DH, Ramsay ID. The importance of adequate serum ferritin levels during oral cyproterone acetate and ethinyl oestradiol treatment of diffuse androgen-dependent alopecia in women. Clin Endocrinol (Oxf). 1992;36(4):421-427.

78. Karrer-Voegeli S, Rey F, Reymond MJ, Meuwly JY, Gaillard RC, Gomez F. Androgen dependence of hirsutism, acne, and alopecia in women: retrospective analysis of 228 patients investigated for hyperandrogenism. Medicine (Baltimore). 2009;88(1):32-45. 
79. Vexiau P, Chaspoux C, Boudou P, et al. Effects of minoxidil $2 \%$ vs cyproterone acetate treatment on female androgenetic alopecia: a controlled, 12-month randomized trial. Br J Dermatol. 2002;146(6):992-999.

80. Scheinfeld N. A review of hormonal therapy for female pattern (androgenic) alopecia. Dermatol Online J. 2008;14(3):1.

81. Simard J, Luthy I, Guay J, Bélanger A, Labrie F. Characteristics of interaction of the antiandrogen flutamide with the androgen receptor in various target tissues. Mol Cell Endocrinol. 1986;44(3):261-270.

82. Paradisi R, Porcu E, Fabbri R, Seracchioli R, Battaglia C, Venturoli S. Prospective cohort study on the effects and tolerability of flutamide in patients with female pattern hair loss. Ann Pharmacother. 2011;45(4):469-475.

83. Yazdabadi A, Sinclair R. Treatment of female pattern hair loss with the androgen receptor antagonist flutamide. Australas $J$ Dermatol 2011;52(2):132-134.

84. Xalatan [package insert]. New York, NY: Pfizer Inc; August 2011.

85. Travatan [package insert]. Fort Worth, TX: Alcon Laboratories Inc; Sep 2011.

86. Lumigan [package insert]. Irivine, CA: Allergan Inc; 2012.

87. Latisse [package insert]. Irivine, CA: Allergan Inc; 2012.

88. Massaki AB, Fabi SG, Fitzpatrick R. Repigmentation of hypopigmented scars using an erbium-doped 1,550-nm fractionated laser and topical bimatoprost. Dermatol Surg. 2012;38(7 Pt 1):995-1001.

89. Cohen JL. Enhancing the growth of natural eyelashes: the mechanism of bimatoprost-induced eyelash growth. Dermatol Surg. 2010;36(9):1361-1371.

90. Johnstone MA, Albert DM. Prostaglandin-induced hair growth. Surv Ophthalmol. 2002;47 Suppl 1:S185-S202.

91. Uno H, Zimbric ML, Albert DM, Stjernschantz J. Effect of latanoprost on hair growth in the bald scalp of the stump-tailed macacque: a pilot study. Acta Derm Venereol. 2002;82(1):7-12.

92. Blume-Peytavi U, Lönnfors S, Hillmann K, Garcia Bartels N. A randomized double-blind placebo-controlled pilot study to assess the efficacy of a 24 -week topical treatment by latanoprost $0.1 \%$ on hair growth and pigmentation in healthy volunteers with androgenetic alopecia. J Am Acad Dermatol. 2012;66(5):794-800.

93. Emer JJ, Stevenson ML, Markowitz O. Novel treatment of femalepattern androgenetic alopecia with injected bimatoprost $0.03 \%$ solution. J Drugs Dermatol. 2011;10(7):795-798.

94. Allergan. Safety and Efficacy Study of Bimatoprost in the Treatment of Women With Female Pattern Hair Loss. Available from http:// clinicaltrials.gov/ct2/show/NCT01325350. NLM identifier: NCT01325350. Accessed April 9, 2013.

95. Faghihi G, Andalib F, Asilian A. The efficacy of latanoprost in the treatment of alopecia areata of eyelashes and eyebrows. Eur $J$ Dermatol. 2009;19(6):586-587.

96. Coronel-Pérez IM, Rodríguez-Rey EM, Camacho-Martínez FM. Latanoprost in the treatment of eyelash alopecia in alopecia areata universalis. J Eur Acad Dermatol Venereol. 2010;24(4):481-485.

97. Piérard-Franchimont C, De Doncker P, Cauwenbergh G, Piérard GE. Ketoconazole shampoo: effect of long-term use in androgenic alopecia. Dermatology. 1998;196(4):474-477.

98. Khandpur S, Suman M, Reddy BS. Comparative efficacy of various treatment regimens for androgenetic alopecia in men. $J$ Dermatol. 2002;29(8):489-498.

99. Jiang J, Tsuboi R, Kojima Y, Ogawa H. Topical application of ketoconazole stimulates hair growth in $\mathrm{C} 3 \mathrm{H} / \mathrm{HeN}$ mice. $J$ Dermatol. 2005;32(4):243-247.

100. Debruyne FM, Witjes FA. Ketoconazole high dose (HD) in the management of hormonally pretreated patients with progressive metastatic prostate cancer. Prog Clin Biol Res. 1987;243A:301-313.

101. Conrad F, Paus R. Estrogens and the hair follicle. J Dtsch Dermatol Ges. 2004;2(6):412-423.

102. Yip L, Zaloumis S, Irwin D, et al. Association analysis of oestrogen receptor beta gene (ESR2) polymorphisms with female pattern hair loss. Br J Dermatol. 2012;166(5):1131-1134.
103. Robbins C, Mirmirani P, Messenger AG, et al. What women want quantifying the perception of hair amount: an analysis of hair diameter and density changes with age in caucasian women. $\mathrm{Br} J$ Dermatol. 2012;167(2):324-332.

104. Kondo S, Hozumi Y, Aso K. Organ culture of human scalp hair follicles: effect of testosterone and oestrogen on hair growth. Arch Dermatol Res. 1990;282(7):442-445.

105. Conrad F, Ohnemus U, Bodo E, et al. Substantial sex-dependent differences in the response of human scalp hair follicles to estrogen stimulation in vitro advocate gender-tailored management of female versus male pattern balding. J Investig Dermatol Symp Proc. 2005;10(3):243-246.

106. Mirmirani P. Hormonal changes in menopause: do they contribute to a 'midlife hair crisis' in women? Br J Dermatol. 2011;165 Suppl 3: $7-11$.

107. Nissimov J, Elchalal U. Scalp hair diameter increases during pregnancy. Clin Exp Dermatol. 2003;28(5):525-530.

108. Adenuga P, Summers P, Bergfeld W. Hair regrowth in a male patient with extensive androgenetic alopecia on estrogen therapy. J Am Acad Dermatol. 2012;67(3):e121-e123.

109. Gassmueller J, Hoffmann R, Webster A. Topical fulvestrant solution has no effect on male and postmenopausal female androgenetic alopecia: results from two randomized, proof-of-concept studies. Br J Dermatol. 2008;158(1):109-115.

110. Blume-Peytavi U, Kunte C, Krisp A, Garcia Bartels N, Ellwanger U, Hoffmann R. Comparison of the efficacy and safety of topical minoxidil and topical alfatradiol in the treatment of androgenetic alopecia in women. J Dtsch Dermatol Ges. 2007;5(5):391-395.

111. Blumeyer A, Tosti A, Messenger A, et al; European Dermatology Forum (EDF). Evidence-based (S3) guideline for the treatment of androgenetic alopecia in women and in men. J Dtsch Dermatol Ges. 2011;9 Suppl 6:S1-S57.

112. Aoi $\mathrm{N}$, Inoue $\mathrm{K}$, Chikanishi $\mathrm{T}$, et al. $1 \alpha, 25$-dihydroxyvitamin D3 modulates the hair-inductive capacity of dermal papilla cells: therapeutic potential for hair regeneration. Stem Cells Transl Med. 2012;1(8):615-626.

113. Finner AM. Nutrition and hair: deficiencies and supplements. Dermatol Clin. 2013;31(1):167-172.

114. Rajput RJ. Controversy: is there a role for adjuvants in the management of male pattern hair loss? J Cutan Aesthet Surg. 2010;3(2): 82-86.

115. Rogers NE, Avram MR. Medical treatments for male and female pattern hair loss. J Am Acad Dermatol. 2008;59(4):547-566.

116. Limat A, Suormala T, Hunziker T, Waelti ER, Braathen LR, Baumgartner R. Proliferation and differentiation of cultured human follicular keratinocytes are not influenced by biotin. Arch Dermatol Res. 1996;288(1):31-38.

117. Tafur J, Mills PJ. Low-intensity light therapy: exploring the role of redox mechanisms. Photomed Laser Surg. 2008;26(4) 323-328.

118. Avram MR, Rogers NE. The use of low-level light for hair growth: part I. J Cosmet Laser Ther. 2009;11(2):110-117.

119. Oron U, Ilic S, De Taboada L, Streeter J. Ga-As (808 nm) laser irradiation enhances ATP production in human neuronal cells in culture. Photomed Laser Surg. 2007;25(3):180-182.

120. Bernstein EF. Hair growth induced by diode laser treatment. Dermatol Surg. 2005;31(5):584-586.

121. Garg S, Messenger AG. Alopecia areata: evidence-based treatments. Semin Cutan Med Surg. 2009;28(1):15-18

122. Hairmax.com [homepage on the Internet]. Boca Raton: Lexington International LLC; 2001-2013. Available from: http://www.hairmax. com. Accessed April 11, 2013.

123. Leavitt M, Charles G, Heyman E, Michaels D. HairMax LaserComb laser phototherapy device in the treatment of male androgenetic alopecia: a randomized, double-blind, sham device-controlled, multicentre trial. Clin Drug Investig. 2009;29(5):283-292. 
124. Satino J. Markou M. Hair regrowth and increased hair tensile strength using the HairMax laser comb for low-level laser therapy. International Journal of Cosmetic Surgery and Aesthetic Dermatology. 2003;5(2):113-117.

125. Kim H, Choi JW, Kim JY, Shin JW, Lee SJ, Huh CH. Low-level light therapy for androgenetic alopecia: a 24-week, randomized, double-blind, sham device-controlled multicenter trial. Dermatol Surg. Epub April 3, 2013.
126. Unger WP, Unger RH. Hair transplanting: an important but often forgotten treatment for female pattern hair loss. J Am Acad Dermatol. 2003;49(5):853-860.

127. Avram MR, Cole JP, Gandelman M, et al; Roundtable Consensus Meeting of The 9th Annual Meeting of The International Society of Hair Restoration Surgery. The potential role of minoxidil in the hair transplantation setting. Dermatol Surg. 2002;28(10):894-900.

\section{Publish your work in this journal}

The International Journal of Women's Health is an international, peerreviewed open-access journal publishing original research, reports, editorials, reviews and commentaries on all aspects of women's healthcare including gynecology, obstetrics, and breast cancer. The manuscript management system is completely online and includes a very quick and fair peer-review system, which is all easy to use. Visit http://www.dovepress.com/testimonials.php to read real quotes from published authors.

Submit your manuscript here: http://www.dovepress.com/international-journal-of-womens-health-journal 